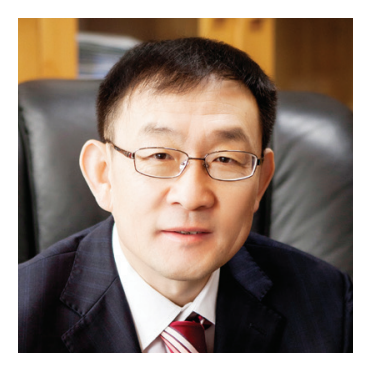

\title{
How China will protect one-quarter of its land
}

\author{
Other nations could learn from China's red-line initiative to preserve nature, \\ biodiversity and ecosystem services in the country, says Jixi Gao.
}

$\mathrm{C}$ hina's dramatic growth has brought staggering air and water pollution. So some people are surprised to learn of a major initiative to protect more than one-quarter of the Chinese mainland - an area almost the size of France, Spain, Turkey, Germany and Italy combined, totalling more than 2.4 million square kilometres.

Called the China Ecological Conservation Red Line (ECRL), the initiative began in 2011, building on ten years of local practice and drawing on economic, population, ecological and other government and academic data. The ECRL implements strategies I developed in 2010 to identify and protect important ecological systems. Plans are already in place for 15 provinces, including Beijing and the Yangtze River economic area. The rest will be completed by the end of the year.

Next year's landmark Convention on Biological Diversity (CBD) will be held in China for the first time since going into force in 1993. It will set the global game plan for preserving nature over the next decade: a major focus is innovation around biodiversity and land degradation. Past biodiversity targets have not been met, and the 2020 CBD meeting needs to put forward goals that are both ambitious and practical. The red-line approach could be instructive, because it is designed to protect almost all rare and endangered species and their habitats in China.

How did this scale of environmental commitment come about? China's swift economic growth has lifted hundreds of millions of people out of poverty, but at a significant cost to the health and well-being of people and places. This was brought home in 1998, when flooding in the Yangtze River basin killed more than 3,000 people and caused in excess of US $\$ 20$ billion in economic damage.

In the past, we would have responded by building ever-higher dams and levees. But after this flood, something different happened: some other environmental scientists and I were included in reconstruction talks with government leaders, and we demonstrated that ecosystem deterioriation had exacerbated the floods. Over-grazing and deforestation had reduced the capacity of grasslands to absorb run-off; wetlands, had been lost to development, along with their ability to limit floods.

That marked the start of a national shift, creating what the Chinese government has dubbed an eco-civilization, in which humanity lives in harmony with nature. In 2000, I launched ECRL ecology-based zoning in Anji County in Zhejiang province, which eventually expanded to the Pearl River delta and about 20 other municipal areas. By 2013, the ECRL delimitation technology and methods had been formulated and applied in four pilot provinces. In 2017, I led efforts with my team to take it national, developing top-level strategies for weighing which environmental regions provide the highest value for nature and humans.

These efforts are based on scientific assessments that consider many dimensions: biodiversity, susceptibility to erosion, crucial ecosystem services (such as pollination and soil conservation) and resilience to natural disasters. Areas to be protected are chosen for their biodiversity and natural beauty; ecosystem services, including access to fresh water; or the environmental capacity to buffer natural disasters such as flooding and sandstorms. The initiative then draws stringent boundaries around these areas to protect them from industrialization and urbanization. It also looks to restore ecologically fragile areas and protect human settlements. Some of the areas to be protected are remote. Many are not.

Around the Yangtze River delta, 28,995 square kilometres of land is set aside for protection, including Yangtze River shorelines, important wetland forest and grassland. The region is home to 150 million people (about $11 \%$ of China's population), and is responsible for $20 \%$ of its gross domestic product (GDP). The red-lined area for the Bohai Economic Rim region (which includes Beijing) covers roughly $37 \%$ of the sea area and $31 \%$ of its coastline and interior land.

National mandates protect designated areas, but the buy-in of local authorities is essential: they are responsible for its implementation. Sometimes this means making difficult choices. Some people living in designated land have to be relocated. Some industries must be shut down. For example, 314 square kilometres of aquaculture farms in the Jiangsu Yancheng Wetland National Natural Reserve are slated to cease operation.

Some doubt that such an ambitious programme can succeed, but the concept of ecological redlining is already written into environmental- and security-protection laws, a legal status that will be hard to circumvent. And China's red-line initiatives are rare and serious designations: its most famous initiative was the one-child policy.

I have been pleasantly surprised by how readily local authorities have accepted, and even welcomed, this policy. In inner Mongolia, for example, herders have seen grasslands destroyed by the mining and petroleum industries. They want a better life and cleaner land more than an increase in GDP.

There is much to do. Last century, more than $10 \%$ of China's mudflats and wetlands were lost to development, and more than 100,000 square kilometres of grasslands were degraded. According to the 2015 red list of China's vertebrates, at least 900 vertebrate species are threatened - more than $20 \%$ of those assessed. And $43.1 \%$ of amphibian species in the country are designated as threatened, compared with $32.5 \%$ globally.

We expect these numbers to improve once the red-line policies are fully in place. The ECRL represents the sort of ambition and sophistication necessary to ensure a healthy planet. I hope other countries will follow China's lead..

Jixi Gao is chief scientist of the ECRL expert committee and director of the Nanjing Institute of Environmental Sciences in China.

e-mail:gjx@nies.org 